\title{
Crawling Across a Meadow
}

\author{
Steven N. Handel
}

T hey crawl across the ground, searching, discovering new targets, blanketing an area, dominating. They can overwhelm restoration projects, destroying hoped-for biodiversity and carefully rendered designs. They succeed in forcing their influence over our actions. They make us fail at predicting what our projects will look like.

These are the clonal species that can sweep through our restoration sites. We are schooled in the importance of seed production and seedling emergence as the reproductive processes that create the vegetation around us. But many plants, most species in some habitats, kiss off sexual reproduction and engulf our landscapes by vegetative growth, clonality.

Both woody and herbaceous plants, use vegetative reproduction as the main process to increase stems, ramets, in a population. Spreading by underground rhizomes or above-ground stolons, even creating new individuals by fragments that can disperse and then root, clonal plants can come to dominate a landscape even if the seed supply of that species was sparse. Clonal integration allows new shoots to obtain resources from already established ramets and explore a wide landscape until favorable microhabitats are discovered. These plants explore space, belying the dogma that only animals can move. The clones in this way can persist for decades. Some herbaceous clones are estimated to be hundreds of years old.

The practitioner starts with a preferred biodiversity, and often a carefully specified seed mix, but the differential clonal growth reshuffles the deck of biodiversity. Relative numbers among species will change and sometimes only a few species may persist. Some clonal species are so aggressive that they can completely dominate a landscape yielding a biodiversity of one locally, as a wave of that species suffocates all the other vegetation. Many ecologists have experienced populations of kudzu (Pueraria spp.) or porcelainberry (Ampelopsis brevipedunculata) or Phragmites (Phragmites australis) and marvel at the power of these clonal plants, while struggling to understand how a more useful plant community can be installed and managed.

Ecological Restoration Vol. 38, No. 1, 2020

ISSN 1522-4740 E-ISSN 1543-4079

(C2020 by the Board of Regents of the University of Wisconsin System.

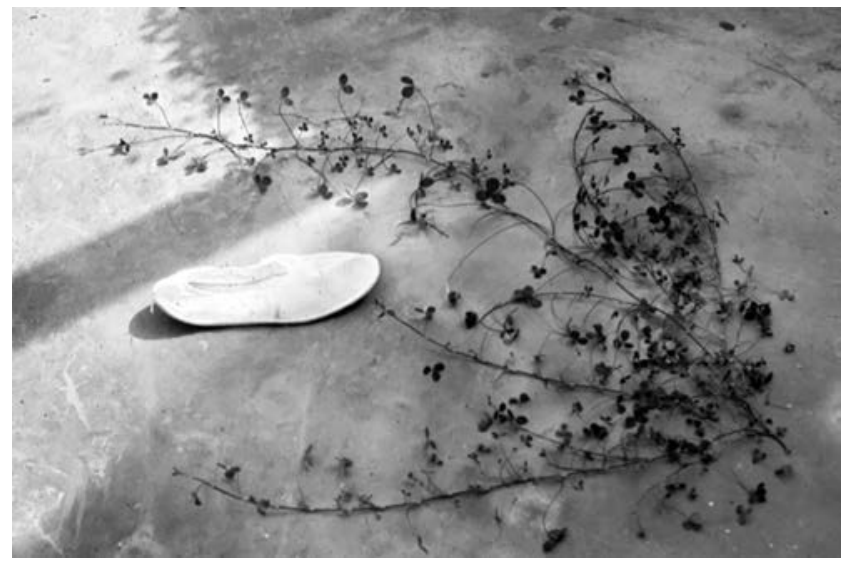

Clones of white clover (Trifolium repens) wander across the soil surface, rooting and expanding when microsites are available (photo by S. Handel).

Some authors have used the idiom of warfare to describe how clonal plants can come to dominate. A "phalanx" of shoots moves in a tight front pushing aside other plant species in a landscape battle until one clone controls the field. Sometimes the clonal growth is diffuse and exploratory, the "guerrilla" strategy of clones, searching for a weakness in the vegetation, until an open spot on the land is found, and the clone takes root and locally expands. The pastoral nature of the meadow is better described as an endless struggle among neighbors for clonal dominance and a momentary landscape victory.

Beneath the soil surface, exploring the ground along with rhizomes of the plants visible to our eyes, are the networks of fungal hyphae which also clonally explore the land. Some latch on to the roots of the plants as mycorrhiza, mutualists which increase the growth and performance of both plant and fungus, while others are effectively pathogens, weakening some plants in the battle for space on the landscape. It has been shown that the biodiversity of fungi in the soil plays a major role in controlling the biodiversity of plants in an area. Longtime studies on plant-plant competition now must be married to an understanding of the fungal world's role in controlling the biodiversity of the habitats we see. The clonal growth of the fungi weaves through the clonal growth structures of many plant species to create a complex tapestry that shimmers and reforms through time. The growth rates of the clones of plants and fungi are not comparable. The landscape patterning shifts as different species obtain momentary advantages until the 
environment changes and then once uncommon species may leap ahead in population size.

One commiserates with the landscape architect whose site plans detail the position of each plant installed in the aesthetic pattern that the designer wishes to champion. Over time, the differential clonal growth rates of the initial plant palette's members overwhelm the designer's dream and he or she awakes to a landscape which is the product of ecological process, not creative preferences. The shifting mosaic of species may represent the product of environmental battles while the designer's landscape theory is lost. We sometimes tell landscape managers that we can install hundreds of plants at the start of a project but after ten years most may be gone as others win these clonal battles. This is not failure but an honest recognition that for the living plant, a landscape design is simply the starting line of an intense race among some sympatric plant and fungal species.

The differing population biology rates among these plant species does not lead to just a diminution of ecological service, however. In our rapidly changing world with both temperature and precipitation regimes varying from year to year and place to place, the battle among clones means that some will live and some will die. But the winners are not necessarily predictable for any one site. Don't bet on a winner; stochastic hurdles are everywhere. The clone that expands during the wet year may shrivel and fade when rainfall becomes sparse and a xeric-adapted species pulls ahead. In these ways, clonal growth can be seen as a botanical Janus in the landscape. Some years the clone faces forward towards population growth and in other years faces back, retreating in size and aerial dominance as another species advances. But like that Janus of Greek mythology, these two faces are joined and together may yield overall community persistence long after the designer or ecologist has moved on to another project parcel that must be restored. Instead of some finality in structure, the proper expectation for a landscape's fate may be constant changes in this battle. En garde, dear restoration plans.

\section{Recommended Readings}

Dietz, H. and T. Steinlein. 2001. Ecological aspects of clonal growth in plants. Pages 511-530 in Esser K., U. Lüttge, J.W. Kadereit and W. Beyschlag (eds), Progress in Botany. Berlin, Germany: Springer.

Hutchings, M.J. and I.K. Bradbury. 1986. Ecological perspectives on clonal perennial herbs. BioScience 36:178-182.

Lovett Doust, L.L. 1982. The battle strategies of plants. New Scientist 95:81-84.

Song, M. and M. Dong. 2002. Importance of clonal plants in community. Acta Ecologica Sinica 22:1960-1967.

Van Der Heijden, M.G. Klironomos, J.N. Ursic, M. Moutoglis, P. Streitwolf-Engel, R. Boller, et al. 1998. Mycorrhizal fungal diversity determines plant biodiversity, ecosystem variability and productivity. Nature 396:69-72.

Wall, D.H. and J.C. Moore. 1999. Interactions underground: Soil biodiversity, mutualism, and ecosystem processes. BioScience 49:109-117.

Wang, Y.J., H. Müller-Schärer, M. van Kleunen, A.M. Cai, P. Zhang, R. Yan, et al. 2017. Invasive alien plants benefit more from clonal integration in heterogeneous environments than natives. New Phytologist 216:1072-1078.



Phragmites australis. USDA-NRCS PLANTS Database. Hitchcock, A.S. 1950. Manual of the Grasses of the United States. Washington, DC: USDA Miscellaneous Publication No. 200. 